\title{
Advanced optimal by PSO-PI for DC motor
}

\author{
Salam Waley Shneen, Abbas Zghair Salman, Qusay A. Jawad, Haider Shareef \\ University of Technology/Baghdad, Iraq
}

\begin{tabular}{l}
\hline \hline Article Info \\
\hline Article history: \\
Received Jan 3, 2019 \\
Revised Apr 6, 2019 \\
Accepted May 1, 2019 \\
\hline Keywords: \\
DC motor \\
FLC \\
PI controller \\
PSO
\end{tabular}

\begin{abstract}
Interest in the drive system, it used in many applications is increasing day by day. Therefore, many researchers have focused on the analyses, design and control of these systems. In this study, Optimal for Dc motor in drive system control strategy proposed for PSO-PI and fuzzy logic controller (FLC) based Dc motor in drive system. In order to test dynamic performance of PSO-PI based drive System, simulation study carried out by MATLAB/Simulink. The results obtained from the PSO-PI based drive system are not only superior in the rise time, settling time and overshoot but can prevent from voltage and has improved power quality.
\end{abstract}

Copyright () 2019 Institute of Advanced Engineering and Science. All rights reserved.

Corresponding Author:

Salam Waley Shneen,,

Energy and Renewable Energies Technology Center,

University of Technology/Baghdad, Iraq,

52 Industry street, Baghdad, Iraq.

Email: salam_waley73@yahoo.com

\section{INTRODUCTION}

Increasing orientation for the use of Dc motor in industry for many electrical applications, EV,Elevator, Robot .etc. [1-3]. A way controller (PI) in addition to the controller integral relative formulated and implemented, using speed control drive system and a pilot phase. While the new strategy promotes traditional PI control performance to a large extent, and proves to be a model-free approach completely, it also keeps the structure and features of a simple PI controller [4-5]. The use consoles mode instead of FuzzyPI control to improve the performance of engines. To control the speed of motor using fuzzy logic (FL) approach leads to a speed control to improve the dynamic behavior of the motor drive system and immune disorders to download and parameter variations [6-7]. In the drive systems, and gains from the traditional can't usually be set in proportion-integral (PI) controller because of mechanical resonance. As a result, performance degradation control. In our work described in this paper, have been adopted and fuzzy logic controller (FLC) for use in drive systems in order to improve the performance of the DC Motor control. The proposed FLC has been compared with traditional PI control with respect to the DC Motor of response [8-9]. Simulation and experimental results have proved that FLC was proposed is superior to the traditional PI. This FLC can be a good solution for the high-performance DC Motor systems. A modern approach to control the speed of load using particle swarm optimization (PSO) to improve the algorithm parameters observer PI-. Simulate the system under different operating year conditions is prepared and the experimental setup. Use PSO algorithm and optimization make a powerful engine, with faster response and higher resolution dynamic and sensitive to load variation [10]. 


\section{DC MOTOR}

The Motor, It is a device converts electrical energy to mechanical energy or a device that produces rotational force which have been developed for different specific purposes that have brought about one of advance in the fields of technology. It is running by DC source [11-12]. The Motor Classification to, AC (alternating current) electrical motors, DC (Direct Current) motor and Special Types of Motor. DC Motor, the electrical port include the supply voltage $\mathrm{E}$ and current $\mathrm{I}$ is given to the input port and the mechanical port include torque T and speed $\omega$ from output port [13-15]. Model of DC motor as shown in Figure 1.

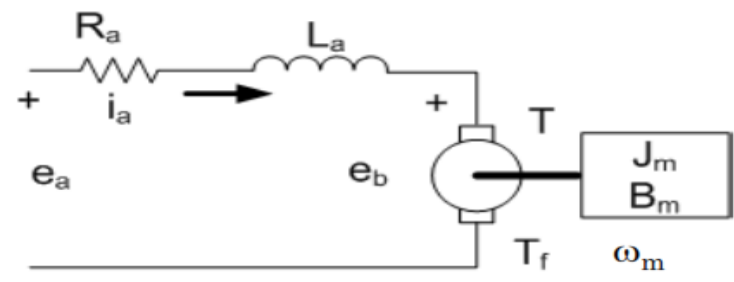

Figure 1. Model of DC Motor

\subsection{Mathematical Model of DC Motor}

In Figure 1, the model of DC motor include the Electrical part and Mechanical part which have Electromechanical Relationships to analysis mathematical model of DC motor by the following (1-11) [16-17]:

$$
\begin{aligned}
& T=K_{T} \cdot i_{a}-T_{f} N-m \\
& e_{a}=i_{a} \cdot R_{a}-e_{b} V \\
& e_{b}=K_{e} \cdot \omega_{m} V \\
& P=\omega_{m} \cdot T V \\
& \omega_{m}=\frac{K_{T} \cdot e_{a}-\left(T-T_{f}\right) \cdot R_{a}}{K_{T} \cdot K_{e}} \\
& \omega_{m}=\frac{e_{a}-i_{a} \cdot R_{a}}{K_{e}} \\
& \omega_{m}=\frac{K_{T} \cdot e_{a}+\left(T_{f}\right) \cdot R_{a}}{K_{T} \cdot K_{e}}
\end{aligned}
$$

Electrical Equations and Mechanical Equations (Electromechanical Relationships) Electrical:

$e_{a}(t)=R_{a} \cdot i_{a}(t)+L \frac{d i_{t}(t)}{d t}+e_{b}(t)$

Mechanical:

$$
T(t)=j_{m} \frac{d \omega_{m}(t)}{d t}+B_{m} \cdot \omega_{m(t)}
$$

Electromechanical:

$$
\begin{aligned}
& e_{b}(t)=K_{E} \cdot \omega_{m}(t) \\
& T(t)=K_{T} \cdot i_{a}(t)
\end{aligned}
$$

Laplace Transform of: 
Electrical;

$$
\begin{aligned}
& E_{a}(s)=L . s . I_{a}(s)+R_{a}+I_{a}(s) \\
& I_{a}(s)=\frac{1}{\text { L.s.R }}\left[E_{a}(s)-E_{b}(s)\right]
\end{aligned}
$$

Mechanical;

$$
\begin{aligned}
& T(s)=\left(j_{m} \cdot s+B_{m}\right) \cdot \omega_{m}(s) \\
& \omega_{m}(s)=\left[1 /\left(j_{m} \cdot s+B_{m}\right)\right] \cdot T(s)
\end{aligned}
$$

Electromechanical;

$$
\begin{aligned}
& e_{b}(s)=K_{E} \cdot \omega_{m}(s) \\
& T(s)=K_{T} \cdot i_{a}(s)
\end{aligned}
$$

Where: $\mathrm{ia}(\mathrm{t})=$ armature current, $\mathrm{eb}(\mathrm{t})=$ back emf, ea $(\mathrm{t})=$ armature terminal voltage, $\omega_{m}=$ motor speed $(\mathrm{rad} / \mathrm{sec}), \mathrm{T}=$ motor torque, $\mathrm{Tf}=$ static friction torque, $\mathrm{Ra}=$ armature resistance, $\mathrm{La}=$ armature inductance, $\mathrm{Jm}=$ rotational inertia, $\mathrm{Bm}=$ viscous friction, $\mathrm{KT}=$ torque constant, $\mathrm{Ke}=$ back emf constant and $\mathrm{P}=$ shaft power.

\subsection{Transfer Function of DC Motor}

A transfer function for a dc motor that relates input voltage to shaft position. The transfer function for an armature controlled dc motor. Represent a mechanical load using a mathematical model. How negative feedback affects dc motor performance.In Figures 2 and 3,Block diagram of DC Motor with load and Block diagram of $\mathrm{DC}$ Motor with no load $(\mathrm{Tf}=0)$. A transfer function of $\mathrm{DC}$ motor by the following $(18-24)[18-20]:$

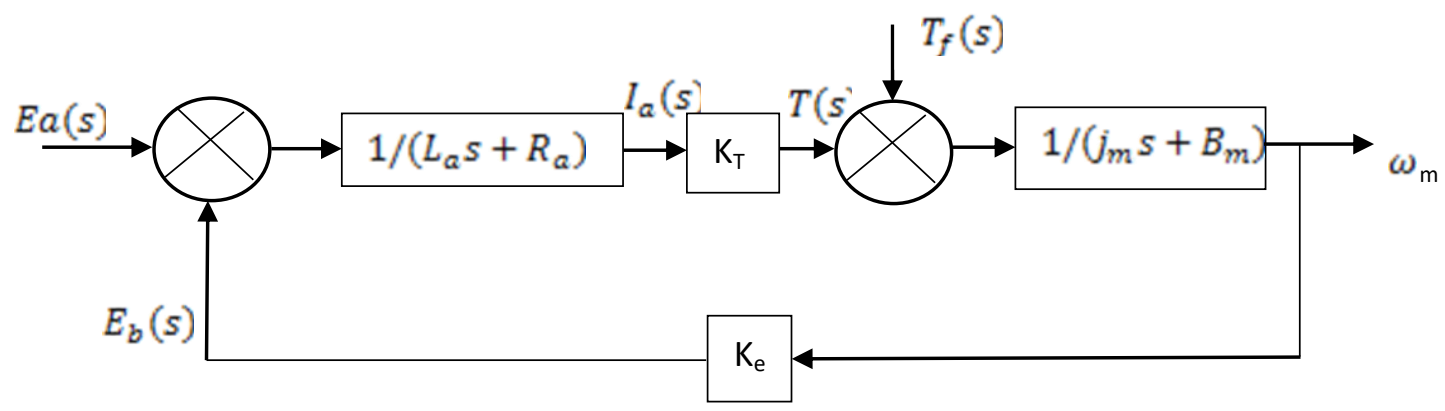

Figure 2. Block diagram of DC Motor with load

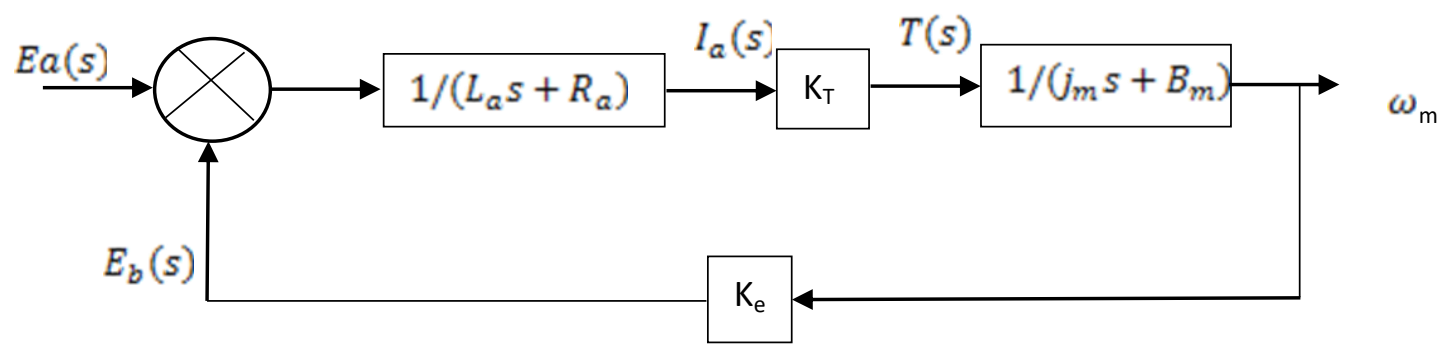

Figure 3. Block diagram of DC Motor with no load $(\mathrm{Tf}=0)$

In (18-21), F.B, F.W and T.F formula: 


$$
\begin{aligned}
& \omega_{m}(s)=G(s) \\
& G(s)=\frac{K_{T}}{\left(L_{a} \cdot s+R_{a}\right)\left(j_{m} \cdot s+B_{m}\right)}
\end{aligned}
$$

F.W formula: $E_{a}(s)=1+G(s) . H(s)$

F.B formula: $H(s)=K_{E}$

T.F formula:

$$
\frac{\omega_{m}(s)}{E_{a}(s)}=\frac{G(s)}{1+G(s) \cdot H(s)}
$$

Simplify T.F formula:

$$
\frac{\omega_{m}(s)}{E_{a}(s)}=\frac{\frac{K_{T}}{\left(L_{a} \cdot s+R_{a}\right)\left(j_{m} \cdot s+B_{m}\right)}}{1+\left[\frac{K_{T}}{\left(L_{a} \cdot s+R_{a}\right)\left(j_{m} \cdot s+B_{m}\right)}\right] \cdot K_{E}}=\frac{K_{T}}{\left(L_{a} \cdot s+R_{a}\right)\left(j_{m} \cdot s+B_{m}\right)+K_{T} \cdot K_{E}}
$$

Final T.F formula:

$$
\frac{\omega_{m}(s)}{E_{a}(s)}=\frac{G(s)}{1+G(s) \cdot H(s)}=\frac{K_{T}}{L_{a} j_{m} \cdot s^{2}+\left(R_{a} j_{m}+B_{m} L_{a}\right) \cdot s+\left(K_{T} \cdot K_{E}+R_{a} \cdot B_{m}\right)}
$$

Parameters of DC motor:

$$
\omega_{m}=500 \mathrm{rad} / \mathrm{s}, I_{a}=2 \mathrm{~A}, K_{e}=0.06 \mathrm{~V} \frac{\mathrm{s}}{\mathrm{rad}}, K_{T}=0.06 \mathrm{~N} \frac{\mathrm{m}}{\mathrm{A}}, \mathrm{Tf}=0.012 \mathrm{~N}-\mathrm{m}, \mathrm{Ra}=1.2 \mathrm{ohm}
$$
,jm=6.2*10-4N-m-s/rad, Bm=1*10-4N-m-s/rad, La=0.02H.

$$
T . F=\frac{\omega_{m}(s)}{E_{a}(s)}=\frac{16.13}{1+0.201 s+0.00333 s^{2}}
$$

\subsection{Parameters Mathematical Results of DC Motor}

Parameters:

$\mathrm{Tf}=0.012 \mathrm{~N}-\mathrm{m}, \mathrm{Ra}=1.2 \mathrm{ohms}, \mathrm{Ke}=0.06 \mathrm{~N}-\mathrm{m} / \mathrm{A}, \mathrm{KT}=0.06 \mathrm{~V}-\mathrm{s} / \mathrm{rad}, \mathrm{ia}=2 \mathrm{~A}$ and $\omega=500 \mathrm{rad} / \mathrm{s}$

Mathematical results:

By using: (1): $\mathrm{T}=(0.06 * 2)-0.012=0.108 \mathrm{~N}-\mathrm{m}$

(2): $\mathrm{e}=(1.2 * 2)+(0.06 * 500)=32.4$ Volt

(4): $\mathrm{P}=500 * 0.108=54$ watt

(7): $\omega \mathrm{m}=(0.06 * 32.4)+[(1.2 * 0.012) /(0.06 * 0.06)]=536 \mathrm{rad} / \mathrm{s}$

\section{OPTIMIZATION AND CONTROLLER}

Optimization and Controller (Classical controller type PI Controller, Expert System type FLC and Optimization type and PSO), Electric system driven is formulated by the motor.

\subsection{PI Controller Modeling}

In the PI controller DC Motor, the actual value is compared with the reference value and the error is the nth sampling interval as [20-21].

$$
\omega e[n]=\omega r^{*}[n]-\omega r[n]
$$

The output of the DC Motor controller gives the reference. Hence the output of DC Motor controller at the nth sampling interval is:

$$
T[n]=T[n-1]+K p(\omega e[n]-\omega e[n-1])+K i . \omega e[n]
$$


For constant air gap flux operation reference quadrature axis current is given as:

$\mathrm{iq}^{*}=\mathrm{T}[\mathrm{n}] / \mathrm{Kt}$

The limiter is used to limit the maximum value of output of speed controller. The maximum machine rated current and device current of the converter dictate the limit. Block diagram of the PI controller as shown in Figure 4.

Where,

$\omega \mathrm{e}[\mathrm{n}]$ is speed error at $\mathrm{nth}$ instant, $\omega \mathrm{r}^{*}[\mathrm{n}]$ is the reference speed at $\mathrm{nth}$ instant

$\omega r[n]$ is the actual machine speed at nth instant, $\omega e[n-1]$ is the speed error at (n-1)th instant

$T[n]$ is the reference torque at nth instant, $T[n-1]$ is the reference torque at (n-1)th instant

$\mathrm{Kp}$ is proportional gain of the speed controller

$\mathrm{Ki}$ is integral gain of the speed controller is reference quadrature axis current

$\mathrm{Kt}$ is torque constant

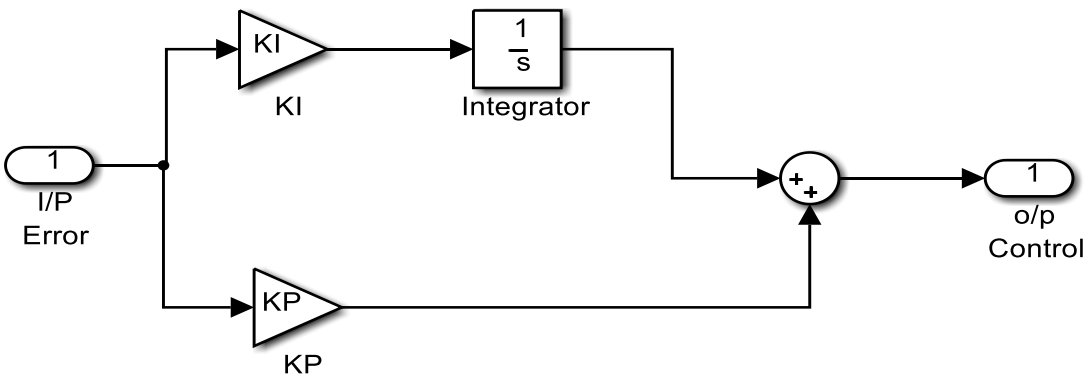

Figure 4. Block diagram of the PI controller

\subsection{Fuzzy Logic Controller}

Fuzzy logic controllers have the following advantages over the conventional controllers that they are cheaper to develop, they cover a wide range of operating conditions, and they are more readily customizable in natural language terms. In Mamdani type FIS the crisp result is obtained by defuzzification, in the Mamdani FIS can be used for both multiple input and single output and multiple inputs multiple outputs system as shown in Figure 5.

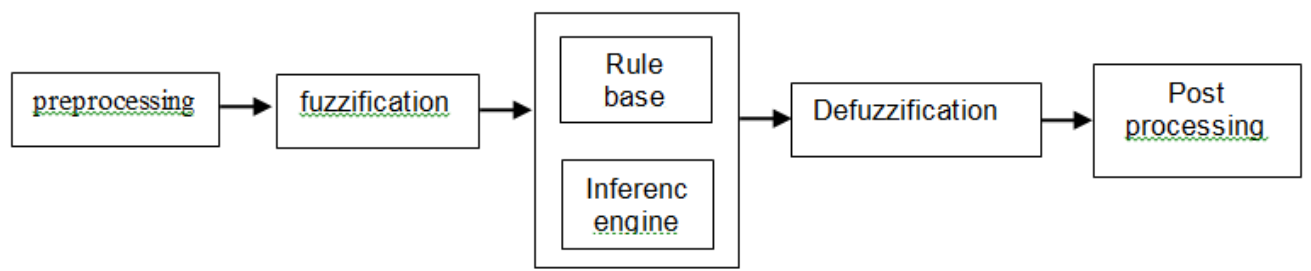

Figure 5. Arrangement of fuzzy logic controller

The usefulness of fuzzy logic controller is adopted especially in a complex and nonlinear system. The rules of conventional FLC are produced depend on the operator's experience or general knowledge of the system in a heuristic way. The thresholds of the fuzzy linguistic variables are usually chosen arbitrarily in the design process. An improper controller value leads to an adverse consequence, unstable mode, collapse and separation. This work propose PSO to design an Optimal Fuzzy Logic Controller OFLC, the optimized criteria is how to minimizing the transient state. The motor in a nonlinear system, time-change and complex system. The PI control is difficult to realize, which needs the accurate mathematical model with synthesizes the fuzzy control and PI control, the parameters can be adjusted deceptively. The FLC has better performance and robustness than conventional PI controller in the servo motor system. Block diagram of FLC- PI controller as shown in Figure 6. It can be overcome by the fuzzy logic controllers. PI control has good 
robustness, simple in structure, and high reliability which suitable for a deterministic system which has accurate mathematical model. The control system performance rely on PI controller parameters [22-23].

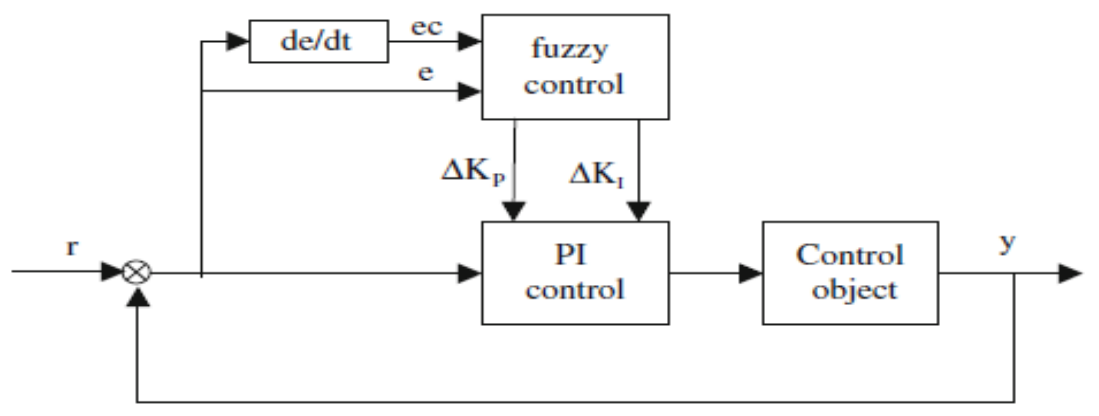

Figure 6. Block diagram of fuzzy PI controller

\subsection{Particle Swarm Optimization}

The biggest characteristic of PSO is in its simple structure, fast convergence, and its ability to prevent falling into a local optimum solution. At the same time, PSO is a random algorithm with a parallel structure. A uniform distribution is used to randomly create a particle swarm. Each particle represents a feasible solution to the problem, the particle swarm refers to the individual's best experience, and the group's best experience, and logically chooses the method it will move itself. After continuous iterations, the particle swarm will gravitate towards the optimum solution. For the ith particle and n-dimensional space can be represented as an (30), the best previous position of its particle is recorded as (31) [24-25]:

$$
\begin{aligned}
& x_{i}=\left(x_{i, 1,} x_{i, 2}, \ldots \ldots x_{i, n}\right)
\end{aligned}
$$

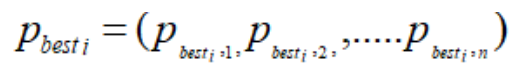

The velocity is an essential part of how PSO work so as modified velocity and position of each particle can be calculated using the current velocity and distance from $\left(\mathrm{P}_{\text {best }_{\mathrm{i}, \mathrm{d}}}\right)$ to $\left(\mathbf{g}_{\text {best }_{\mathbf{d}}}\right)$ :

$$
\begin{aligned}
& V_{i, m}^{(I t+1)}=W^{*} V_{i, m}^{(I t)}+c_{1} * r *\left(p_{\text {besti }, m}-x_{i, m}^{(I t)}\right)+c_{2} * r *\left(g_{\text {besti } i, m}-x_{i, m}^{(I t)}\right) \\
& \left.x_{i, m}^{(I t+1)_{i, m}}=x_{i, m}^{(I t+1)_{i, m}}+V^{(I t)}{ }_{i, m}\right)
\end{aligned}
$$

Where $\mathrm{n}$ is the number of particles in a group; $\mathrm{m}$ is number of Dimension $\mathrm{m}=1,2, \ldots$, ; It is a pointer of iterations (generations); $\mathrm{W}$ is an inertia weight factor; $\mathrm{c} 1, \mathrm{c} 2$ are acceleration constants were often set to be 1.2 according to past experiences; $r$ is random value in the range between $[0,1] ; V_{i, m}^{(I t)}$ : Velocity of particle no. $i$ at iteration It., $x_{i, m}^{\text {(It.) }}$ : Current position of particle $i$ at iteration It. $_{G_{\text {best }}}$ : Global best particle among all the particles in the population. In the above procedures, the parameter determined the resolution, or fitness, with which regions are to be searched between the present position and the target position, the inertia weight is set according to the (32).

$$
W=w_{\max }-\frac{w_{\max }-w_{\min }}{\text { Iter } r_{\max }} \text {.Iter }
$$

Where: Itermax is the maximum number of iterations and Iter is the current number of iterations. 


\section{ADVANCED IMPLEMENTATION FOR DC MOTOR}

To use different control systems, like Classical PI Controller, Expert System Fuzzy Logic Controller and Optimization PSO Controller. It used to control for Implementation for DC Motor. The simulation model for DC motor as shown in Figure 7 and The simulation model as shown in Figures 8-11, by used all types to get the result and analysis it with compared to see the advanced implementation for DC Motor:

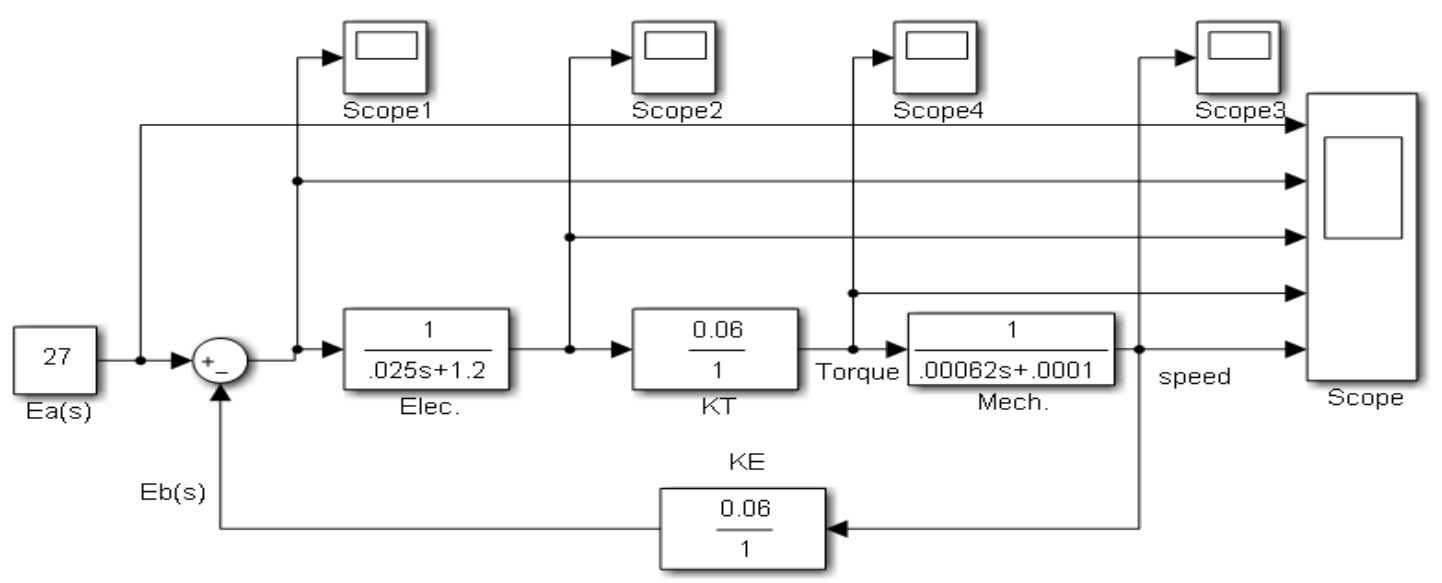

Figure 7. The simulation model for DC Motor

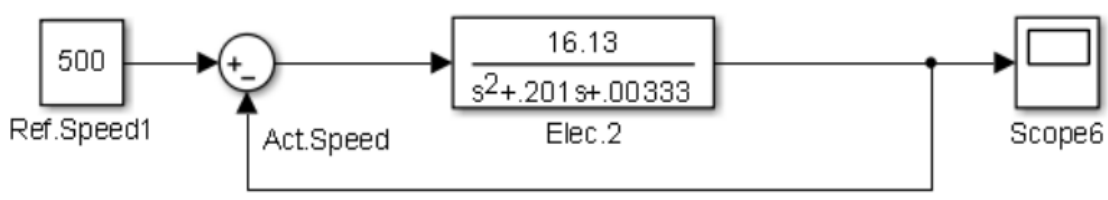

Figure 8. The simulation model for DC Motor without control

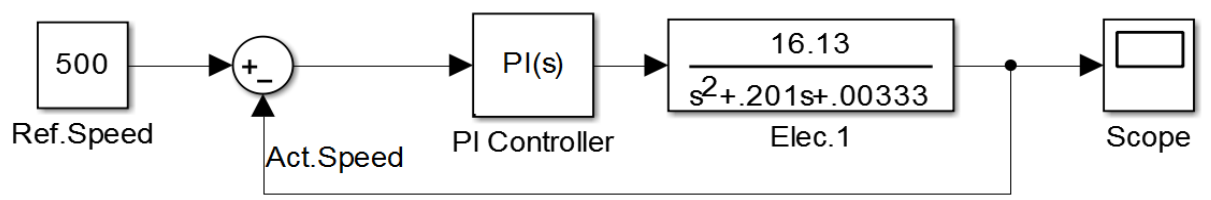

Figure 9. The simulation model for DC Motor with PI control

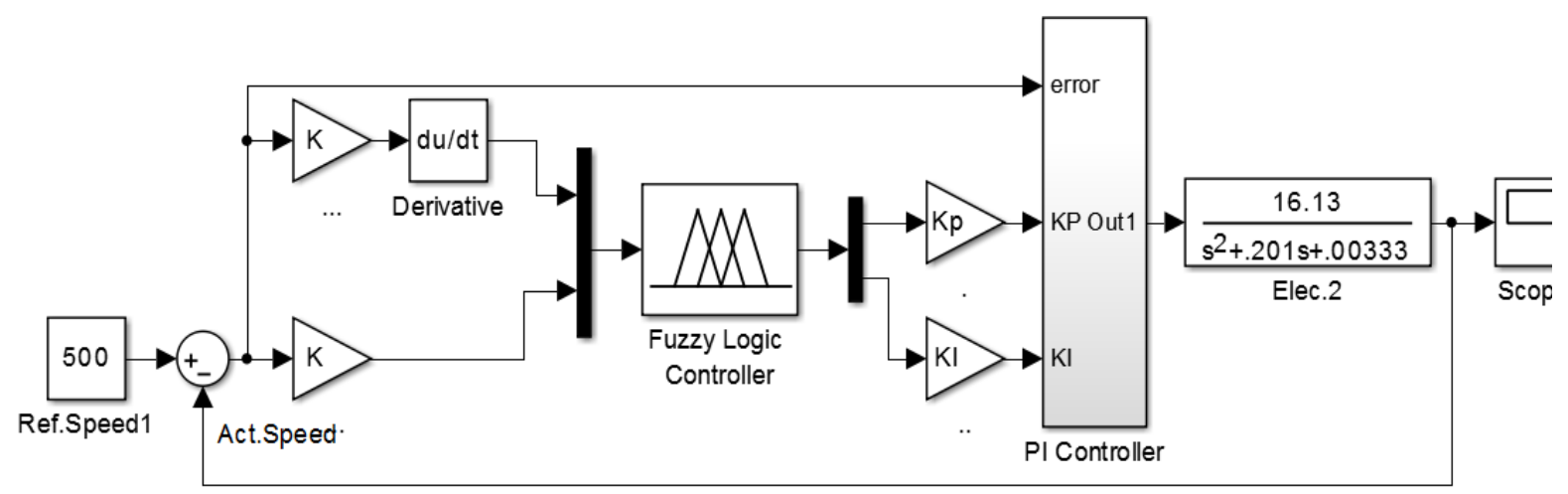

Figure 10. The simulation model For DC Motor with FLC 


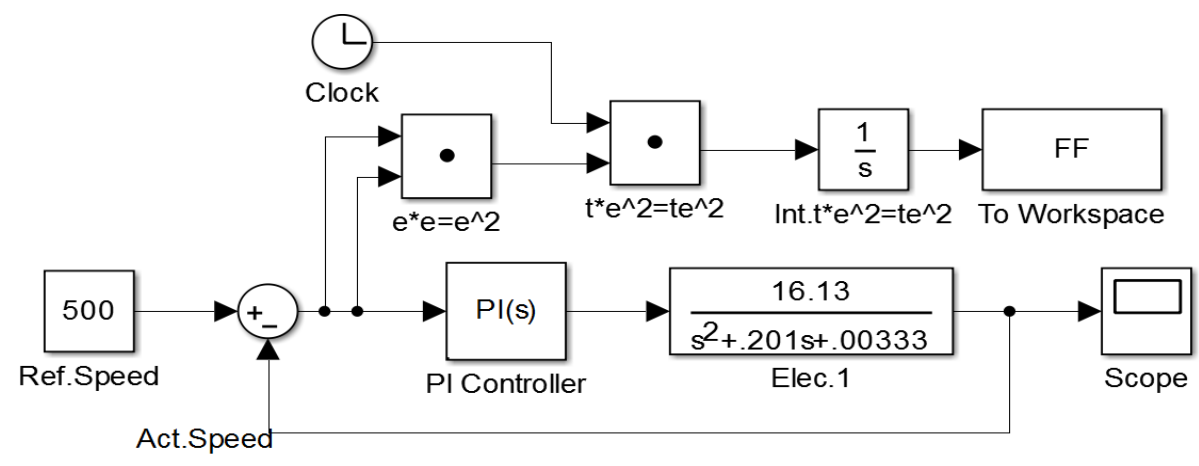

Figure 11.The simulation model For DC Motor with PSO-PI control

\section{RESULTS AND ANALYSIS}

5.1. The simulation Results

\subsubsection{The Simulation Results for DC Motor with in and Without Controller}

By used the simulation model for DC Motor without control in Figure 12 and with PI control to get the simulation results for DC Motor with controller in Figure 13.

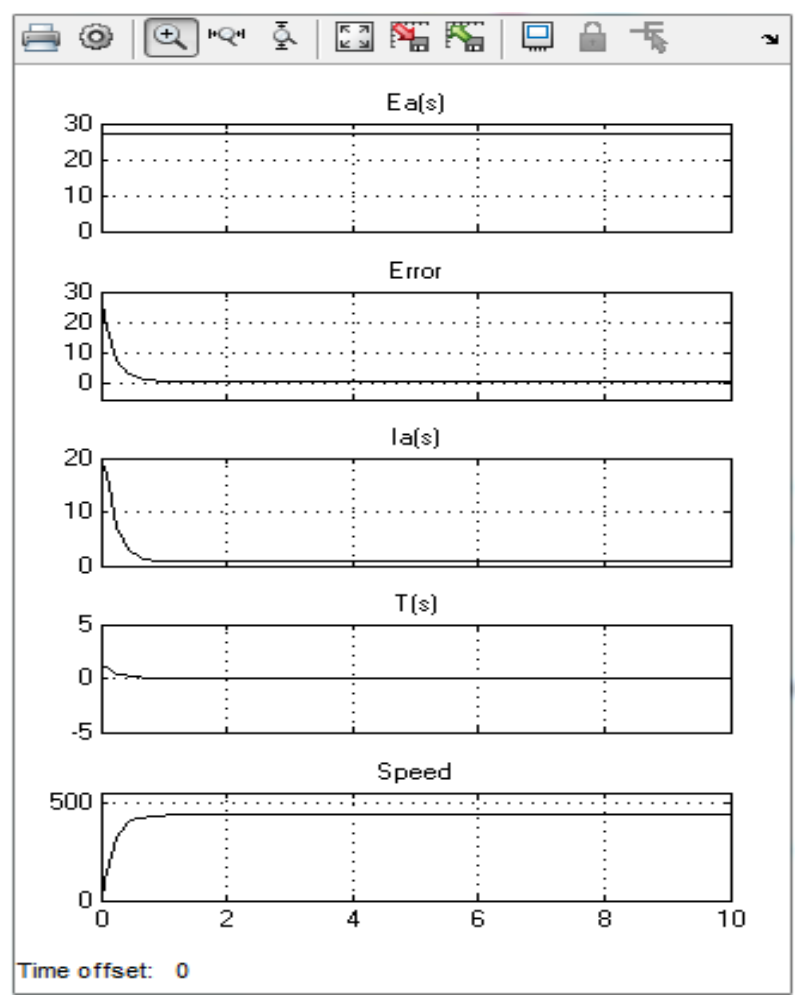

Figure 12. Simulation speed response for T.F of DC Motor without Controller 


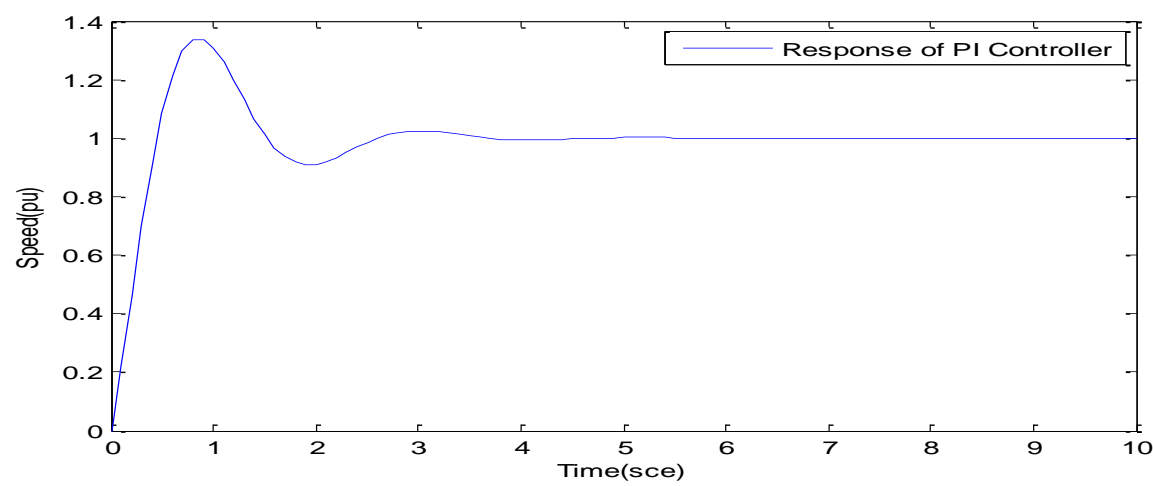

Figure 13. Simulation speed response for T.F of DC Motor with PI Controller

\subsubsection{The simulation Results for De Motor with Optimization}

By used the simulation model for Dc Motor with Optimization to get the simulation results for DC Motor with Optimization in Figures 14 and 15.

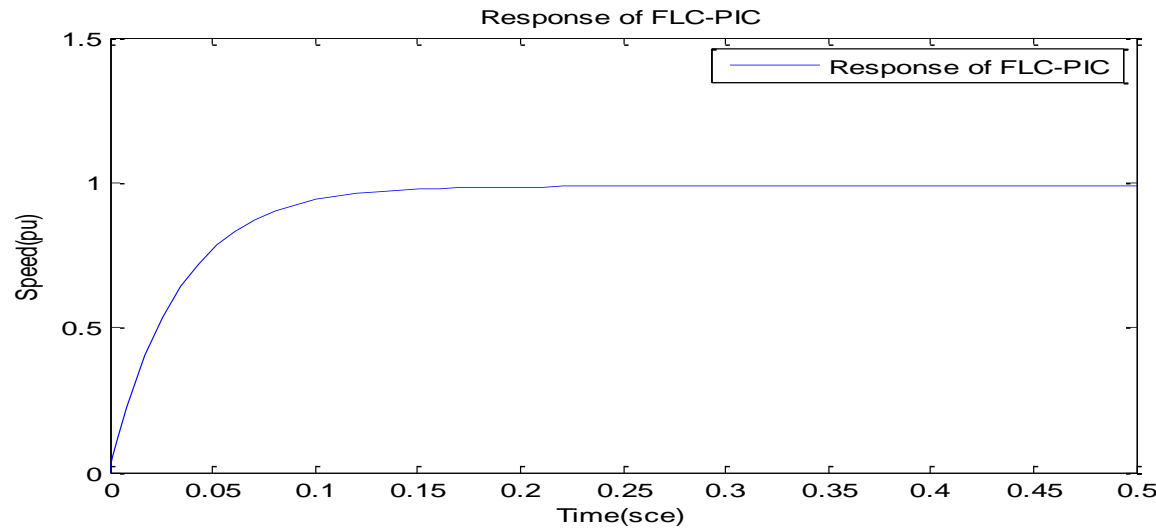

Figure 14. Simulation speed response for T.F of DC Motor with FLC_ PI Controller

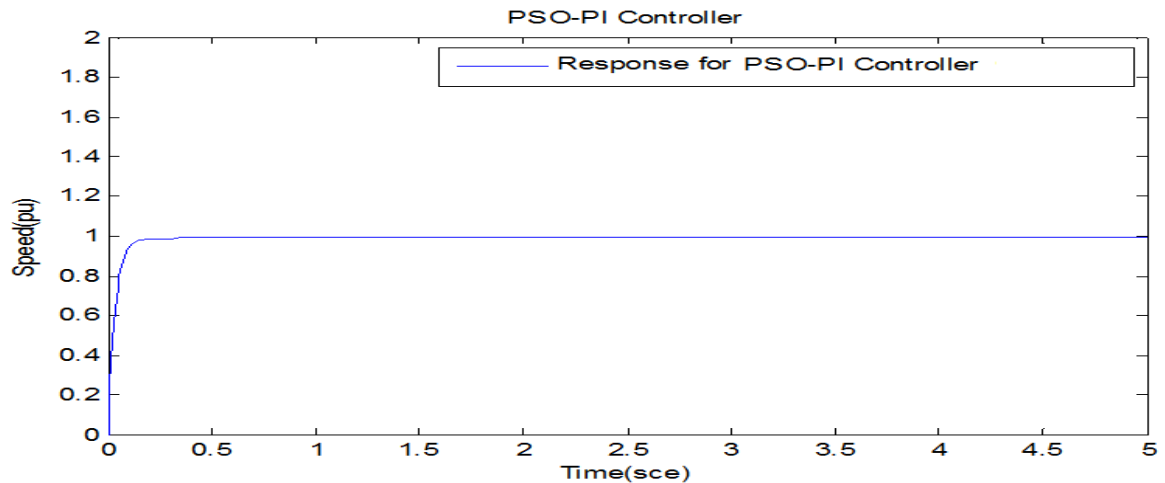

Figure 15. Simulation speed response for T.F of DC Motor with PSO_PI Controller

\subsection{Simulation Analysis}

Final step, use different control systems, Like Classical PI Controller, Expert System Fuzzy Logic Controller and Optimization PSO Controller to analysis all result. Simulation models (Classical PI Controller, Expert System Fuzzy Logic Controller and Optimization PSO Controller of this step as shown in Figures 9-11 and simulation results as shown in Figure 16: Simulation Response (pu) Of PI Control, Fuzzy_ 
PI Control \& PSO_PI Control. The results obtained from the PSO-PI based PES are not only superior in the rise time, settling time and overshoot but can prevent from voltage and has improved power quality.

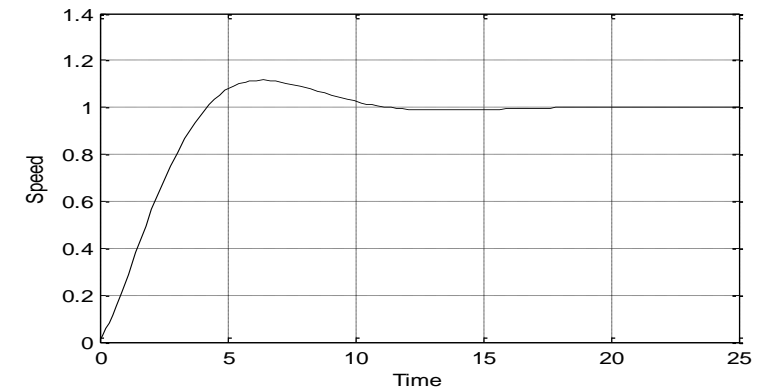

(a) PI Control

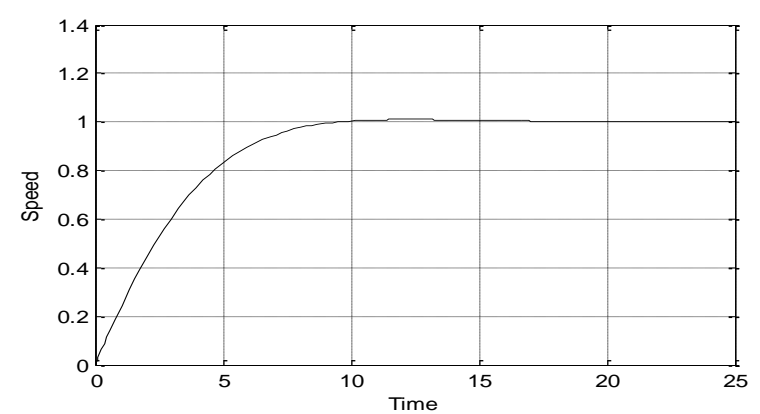

(c) PSO_PI Control

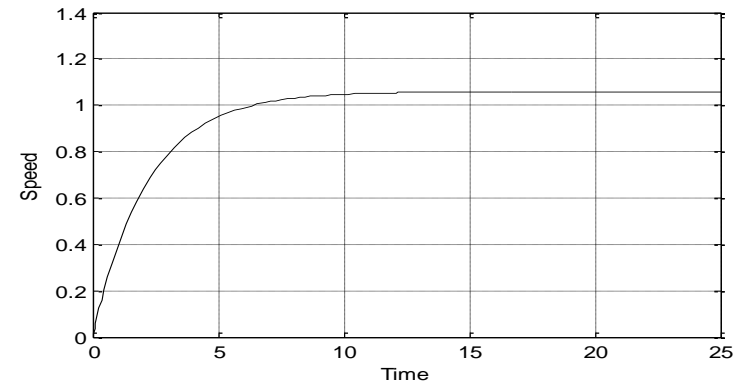

(b) Fuzzy_PI Control

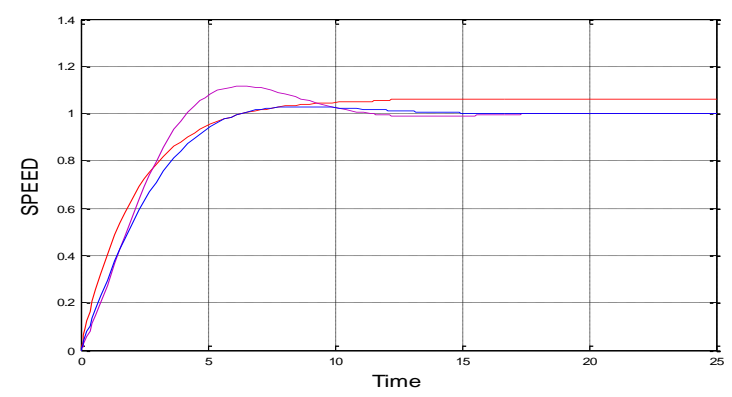

(d) PI Control, Fuzzy_PI Control \&PSO_PI Control

Figure 16. Simulation Response (pu) Of PI Control, Fuzzy_PI Control \&PSO_PI Control

\section{CONCLUSION}

To use different control systems as a case studies. To achieve this objective which characterizes each part of a system such as a DC Motor module, controller and Optimization. After that to investigate the design connection topology for all components of a DC Motor system in order to study the operation of the system for different environmental conditions. The simulation circuits for DC Motor controllers include all realistic components of the system. These results also confirmed that the maximum permissible value. Modeling, analysis, testing and simulation a DC Motor under different conditions using MATLAB. The performance of DC Motor system are controlled and Optimization by PI, fuzzy and PSO.

\section{REFERENCES}

[1] Song, Yun Seong, and Metin Sitti. "STRIDE: A highly maneuverable and non-tethered water strider robot," Robotics and Automation, 2007 IEEE International Conference on. IEEE, 2007.

[2] Liu, Xiaoxing, et al. "Optimal traction control for EV utilizing fast torque response of electric motor," Industrial Electronics Society, 2005. IECON 2005. 31st Annual Conference of IEEE. IEEE, 2005.

[3] Shneen, Salam Waley, Chengxiong Mao, and Dan Wang. "Advanced Optimal PSO, Fuzzy and PI Controller with PMSM and WTGS at 5Hz Side of Generation and 50Hz Side of Grid." International Journal of Power Electronics and Drive Systems (IJPEDS) 7.1 (2016): 173.

[4] Huayong, Yang, Yang Jian, and Xu Bing. "Computational simulation and experimental research on speed control of VVVF hydraulic elevator." Control Engineering Practice 12.5 (2004): 563-568.

[5] Ohm, Dal Y. "PID and PDFF compensators for Motion Control," Conference Record of the 1994 IEEE. Vol. 3. 1994.

[6] Attiya, Adnan Jabbar, Yang Wenyu, and Salam Waley Shneen. "Fuzzy-PID Controller of robotic grinding force servo system." Indonesian Journal of Electrical Engineering and Computer Science (IJEECS) 15.1 (2015): 87-99.

[7] Attiya, Adnan Jabbar, et al. "Variable Speed Control Using Fuzzy-PID Controller for Two-phase Hybrid Stepping Motor in Robotic Grinding." Indonesian Journal of Electrical Engineering and Computer Science (IJEECS) 3.1 (2016): 102-118. 
[8] Montiel, Oscar, et al. "Performance of a simple tuned fuzzy controller and a PID controller on a DC motor." Foundations of Computational Intelligence, 2007. FOCI 2007. IEEE Symposium on. IEEE, 2007.

[9] Shneen S W, Mao C. Artificial Optimal Fuzzy Control Strategy for Elevator Drive System by Using Permanent Magnet Synchronous Motor[J]. TELKOMNIKA Indonesian Journal of Electrical Engineering, 2015, 14(3).

[10] Ibrahim, H. E. A., F. N. Hassan, and Anas O. Shomer. "Optimal PID control of a brushless DC motor using PSO and BF techniques." Ain Shams Engineering Journal 5.2 (2014): 391-398.

[11] Waley, A. Salam, Chengxiong Mao, and C. Dan Wang. "Artificial Optimal Fuzzy Control Strategy for Electric Vehicle Drive System by Using Permanent Magnet Synchronous Motor." International Journal of Engineering and Technology 9.1 (2017): 50.

[12] Attiya, Adnan Jabbar, Yang Wenyu, and Salam Waley Shneen. "PSO_PI Controller of Robotic Grinding Force Servo System." Indonesian Journal of Electrical Engineering and Computer Science (IJEECS) 15.3 (2015): 515-525.

[13] Attiya, Adnan Jabbar, Yang Wenyu, and Salam Waley Shneen. "Compared with PI, Fuzzy-PI and PSO-PI Controllers of Robotic Grinding Force Servo System." Indonesian Journal of Electrical Engineering and Computer Science (IJEECS) 16.1 (2015): 65-74.

[14] M Prita A., et al. "Comparative Study of Fuzzy Logic Based Speed Control of Multilevel Inverter fed Brushless DC Motor Drive". International Journal of Power Electronics and Drive System (IJPEDS), 4(1): 70-80, 2014.

[15] Waley, Salam, Chengxiong Mao, and Nasseer K. Bachache. "Biogeography Based Optimization Tuned Fuzzy Logic Controller to Adjust Speed of Electric Vehicle." Indonesian Journal of Electrical Engineering and Computer Science (IJEECS) 16.3 (2015): 509-519.

[16] Lei Jin-li, "Adaptive Control for Brushless DC Motor Based on Fuzzy Inference". TELKOMNIKA Indonesian Journal of Electrical Engineering, 12(5): 3392-3398, 2014.

[17] M. A. Shamseldin, and A. M. A. Ghany, M. A. A. Ghany, "Performance Study of Enhanced Non-Linear PID Control Applied on Brushless DC Motor," International Journal of Power Electronics and Drive System (IJPEDS), vol. 9, no.2, pp. 536-545, 2018.

[18] Shneen, Jaafar Ali Kadhum Salam Waley, and Mahdi Ali Abdul Hussein. "Utilization of DC motor-AC generator system to convert the solar direct current into $220 \mathrm{v}$ alternating current."

[19] Madadi, Ali, and Mahmood Mohseni Motlagh. "Optimal control of DC motor using grey wolf optimizer algorithm." Technical Journal of Engineering and Applied Science 4.4 (2014): 373-379.

[20] Allaoua, Boumediene, Brahim Gasbaoui, and Brahim Mebarki. "Setting up PID DC motor speed control alteration parameters using particle swarm optimization strategy." Leonardo Electronic Journal of Practices and Technologies 14 (2009): 19-32.

[21] Kanojiya, Rohit G., and P. M. Meshram. "Optimal tuning of PI controller for speed control of DC motor drive using particle swarm optimization." Advances in Power Conversion and Energy Technologies (APCET), 2012 International Conference on. IEEE, 2012.

[22] M. A. A. Ghany, M. A. Shamseldin, and A. M. A. Ghany, "A Novel Fuzzy Self Tuning Technique of Single Neuron PID Controller for Brushless DC Motor," International Journal of Power Electronics and Drive System (IJPEDS), vol. 8, no. 4, pp. 1705-1713, 2017.

[23] Ghany, MA Abdel, Mohamed A. Shamseldin, and AM Abdel Ghany. "A novel fuzzy self tuning technique of single neuron PID controller for brushless DC motor." Power Systems Conference (MEPCON), 2017 Nineteenth International Middle East. IEEE, 2017.

[24] Nasri, Mehdi, Hossein Nezamabadi-Pour, and Malihe Maghfoori. "A PSO-based optimum design of PID controller for a linear brushless DC motor." World Academy of Science, Engineering and Technology 26.40 (2007): 211-215.

[25] El-Gammal, Adel AA, and Adel A. El-Samahy. "A modified design of PID controller for DC motor drives using Particle Swarm Optimization PSO." Power Engineering, Energy and Electrical Drives, 2009. POWERENG'09. International Conference on. IEEE, 2009. 